\title{
Fuel Cell Stack Design Using Carbon Fiber Composites
}

\author{
Yean-Der Kuan, ${ }^{*}$ Chong-Kai Wang, Cheng Yang, \\ Po-Cheng Lee, Yu-Sheng Siao, and Cheng-Yi Lee \\ Department of Refrigeration, Air-Conditioning and Energy Engineering, \\ National Chin-Yi University of Technology, Taichung City, 411, Taiwan
}

(Received July 22, 2020; accepted October 25, 2020)

Keywords: fuel cell stack, carbon fiber composite, bipolar plate, phenolic resin, carbonization

The bipolar plate plays an important role in fuel cells. It has a flow channel that enables hydrogen and oxygen to flow through the reaction area to produce a chemical reaction. The bipolar plate also transmits current. It should have high conductivity, corrosion resistance, and mechanical strength. We used carbon fiber composite materials to make bipolar plates and connected them in series to form a fuel cell stack. The carbon fiber composites were made by coating carbon fiber cloth with a thermosetting resin mixed with carbon powder. Resin is a poor conductor and will affect bipolar plate conductivity. Therefore, carbon powder was added to provide a conductive route via the composite plate material to achieve current transmission. In addition, we performed carbonization to increase the conductivity of the carbon fiber bipolar plate. The finished bipolar plate was placed in a single fuel cell for performance testing. Good test results were obtained with stacked bipolar plates with a membrane electrode assembly (MEA) and a gasket.

\section{Introduction}

Since the Industrial Revolution, global warming caused by the extensive use of fossil fuels has caused sea levels to rise and numerous animals and plants to become extinct. Environmentally friendly and sustainable development is now a major aim. The fuel cell is a type of green energy. During its operation, it only produces water and no other impurities, thus providing an extremely clean energy. The energy conversion efficiency of fuel cells is high. ${ }^{(1)}$ Unlike traditional power generation methods, it does not require the multiple conversion of energy before it is finally converted into the electricity we need. A fuel cell stack consists of layers of stacked fuel cells to increase the voltage to the required working voltage to make the machine operate.

Fuel cell efficiency is determined by many factors, including operational parameters such as electrochemical parameters, cell operating temperature, mass transport, flow rate, and other physical components in the cell stack, such as the membrane electrode assembly (MEA) as well as the bipolar plate. The bipolar plate accounts for almost $70 \%$ of the stack weight

*Corresponding author: e-mail: ydkuan@ncut.edu.tw https://doi.org/10.18494/SAM.2020.3103 
and $30 \%$ of the total cost of cell stacks on the fuel cell market. The geometric bipolar plate design serves as the medium of entry for reactive gases into the fuel cell and also functions as a platform for the easy dissemination of the reactive substance onto the active cell stack surface. The bipolar plate plays a crucial role in the stack, determining the water management for the polymer electrolyte membrane fuel cell (PEMFC), thermal and electrical conductivities, mass transport, and current density distribution. ${ }^{(2)}$ The bipolar plate is the main component that determines the cost, volume, and performance of a PEMFC stack. Carbon composite/ epoxy has been considered a potential material for bipolar plates owing to its good mechanical properties, electrical conductivity, and corrosion resistance. However, the long curing time of the epoxy matrix under high pressure remains an obstacle to mass production. ${ }^{(3)}$ Lim et al. used a spraying method to add natural graphite powder and carbon black as conductive particles to a carbon fiber composite bipolar plate. This effectively reduced the resistance of the bipolar plate bulk and improved the PEMFC performance. ${ }^{(4)}$ Kim et al. mixed fiberboard with carbon black to improve the ductility and flame-treated the surface of a bipolar plate to reduce the surface contact resistance. ${ }^{(5)}$ They also used surface modification technology to place the aluminum and carbon fiber composite material in close contact, thereby reducing the contact resistance. This hybrid bipolar plate has only 3\% of the resistance of a conventional composite bipolar plate. ${ }^{(6)}$ Cho et al. used phenolic epoxy resin, natural graphite powder, and carbon black to make composite bipolar plates for testing, and found that they had good corrosion resistance. ${ }^{(7)}$ Lee et al. used the soft layer method to remove the resin to expose carbon fibers and increase the conductivity of a carbon fiber composite board. ${ }^{(8)}$ Kim et al. coated a bipolar plate with graphite to reduce the contact resistance between the gas diffusion layer and the bipolar plate. ${ }^{(9)}$ Liao et al. made a vinyl ester resin solution reinforced with multiwall carbon nanotubes (MWCNTs) and a bulk molding compound (BMC) with carbon fibers. The unit was then processed after hot pressing. A composite bipolar plate was formed, in which MWCNTs formed a conductive path between the carbon fibers. This helped to improve bipolar plate conductivity. ${ }^{(10)}$ Kakati et al. used phenol formaldehyde resin as the binder, with natural graphite, carbon black, and carbon fibers as reinforcing materials to perform related electrochemical studies. The results of mechanical characteristic measurements showed the feasibility of the binder. ${ }^{(11)}$ Lee mixed two immiscible polypropylene (PP) and polyethylene polymers in the same row (isotactic) to form a sol gel. This was made into a fuel cell with carbon fibers, forming a thermoplastic carbon fiber composite bipolar plate. ${ }^{(12)}$

The fuel cell performance is very important. Qin et al. used the flow network method to build a fuel cell model and optimized the fuel cell stack through experiments. ${ }^{(13)}$ Abdel-Rehim found that a magnetic field can promote the efficiency of fuel cell power generation through a low electric field test on the PEMFC effect. ${ }^{(14)}$ Polak et al. compared the input of pure oxygen at the cathode with that of air and found that the input of pure oxygen resulted in the high performance of a fuel cell. ${ }^{(15)}$

Pukrushpan et al. proposed a dynamic model of a nonlinear fuel cell system suitable for controlled research. ${ }^{(16)}$ Wilberforce et al. designed a fuel cell with a serpentine flow channel plate for testing and discussed the effects of the battery operating temperature, humidity, and other parameters. ${ }^{(17)}$ Rajalakshmi and Dhathathreyan developed a technique of using a 
segmented cell structure to determine the current density distribution in a fuel cell in operation. This technology can help people better understand the distribution of reactants on the active fuel cell area, thereby optimizing the fuel cell performance. ${ }^{(18)}$ Giacoppo et al. tested fuel cell performance by simulating the lunar surface environment, hoping to use fuel cell stacks as a power source to explore the moon in the future. ${ }^{(19)}$ This research work's main purpose is the development of light, efficient, and stable fuel cell stacks. In this system, the bipolar plate that is light and has high conductivity, corrosion resistance, and mechanical strength is necessary. The following description is the production process and test method of a carbon fiber composite bipolar plate.

\section{Materials and Methods}

\subsection{Carbon fiber cloth}

Carbon fiber cloth is the basic material for making a carbon fiberboard. The plain-weave graphite cloth used in this research was produced by TEI Composites Co., Ltd. (model number: TI-3101). Its $\mathrm{K}$ number is 3 (1K means that one bundle of carbon fibers contains 1000 carbon fibers), its fiber areal weight (FAW) is $200 \mathrm{~g}-\mathrm{m}^{-2}$, and its sheet resistance is $20 \Omega / \mathrm{sq}$. The structure of the cloth is shown in Fig. 1.

\subsection{Phenolic resin}

The resin used in this research is the resole-type phenolic resin produced by Kuen Bong Chemical Industry Corp. (model KB-7480). The resin plays the connecting role in fiberboard production and can make the carbon fibers bond tightly. The resin is coated onto the fiber cloth. After the fiber cloth is stacked layer by layer, the resin is cured using a hot press to give the carbon fiberboard greater strength. The chemical structure of the phenolic resin is shown in Fig. 2.

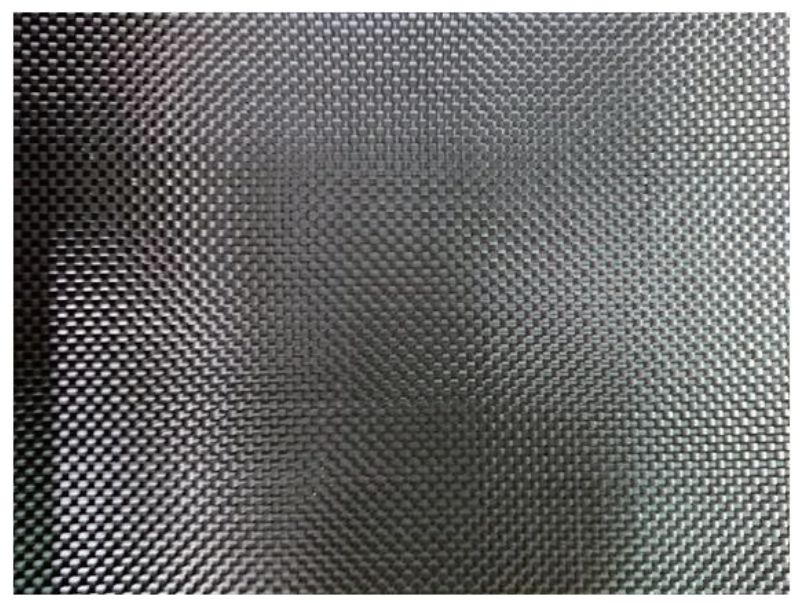

Fig. 1. (Color online) Plain-weave graphite cloth. 


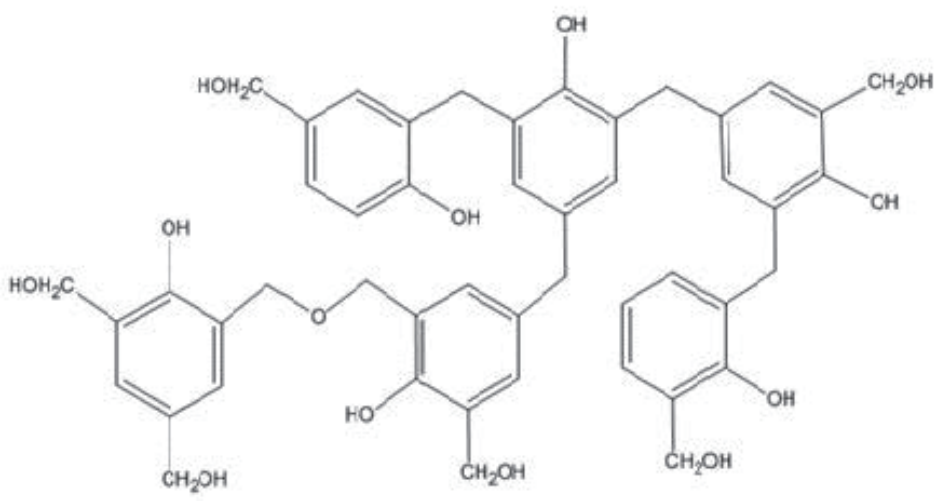

Fig. 2. Chemical structure of phenolic resin.

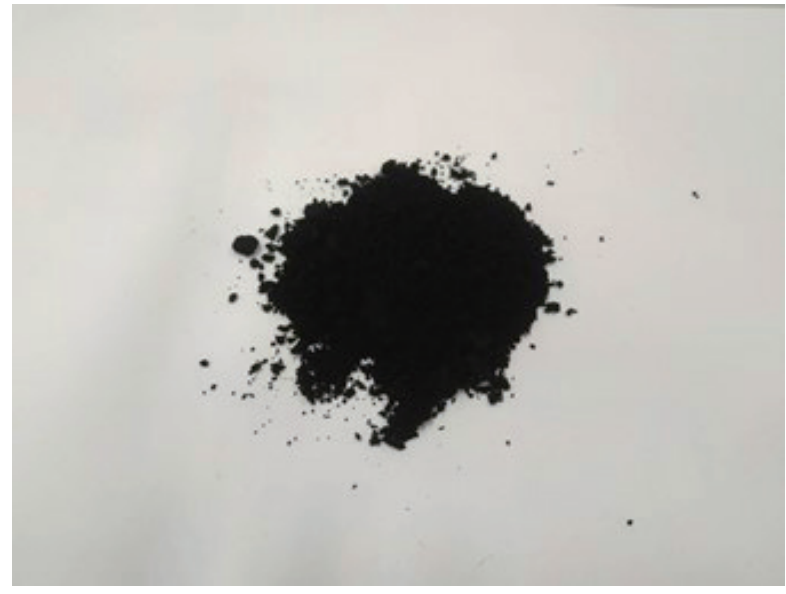

Fig. 3. (Color online) Carbon nanotube powder.

\subsection{Carbon powder}

The carbon nanotube powder used in this study shown in Fig. 3 was purchased from Taiwan Conjutek Co., Ltd. The product name is CRUDE, the tube diameter is $10-50 \mathrm{~nm}$, the tube length is $1-25 \mu \mathrm{m}$, the purity is $\geq 95 \mathrm{vol} \%$, the amorphous carbon content is $<3 \%$, and the specific surface area is $150-250 \mathrm{~m}^{2} \cdot \mathrm{g}^{-1}$. The carbon powder increases the conductivity of the carbon fiberboard. Because the resin is a poor conductor, the carbon powder can establish a conductive channel between the fibers to transmit current.

\section{Model for Testing Fuel Cell Stack}

The fuel cell includes an MEA, a gasket, a bipolar plate, and an end plate. An exploded view of the fuel cell is shown in Fig. 4. 


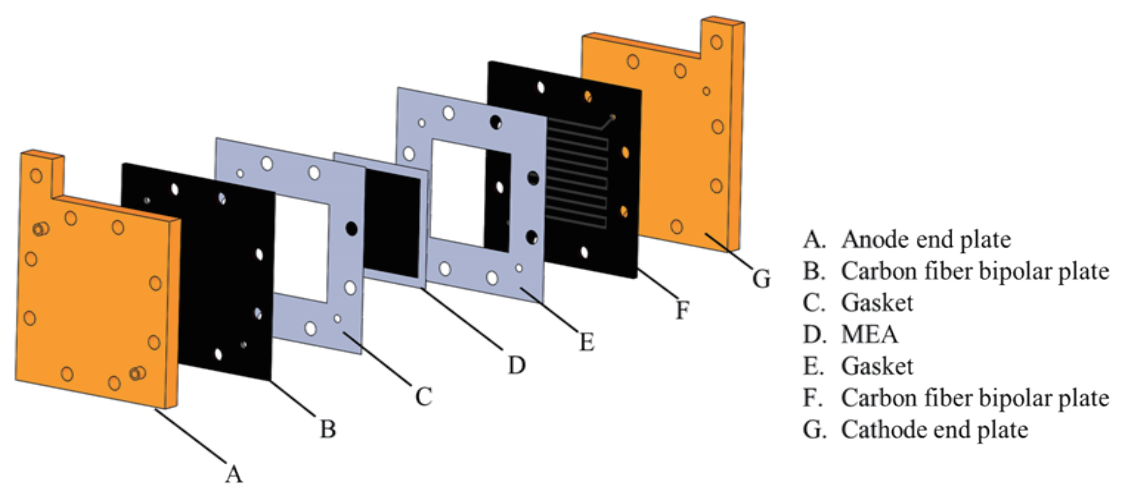

Fig. 4. (Color online) Exploded view of single cell.

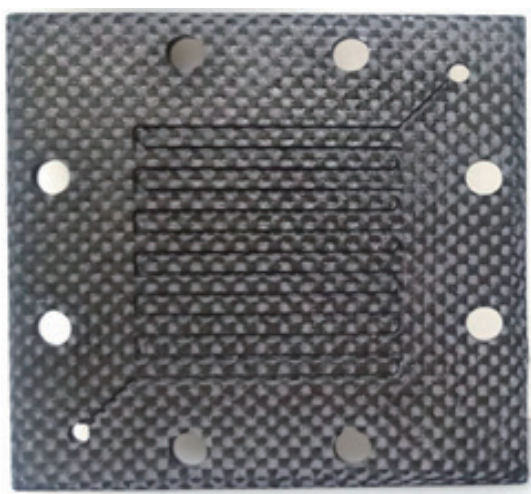

Fig. 5. (Color online) Carbon fiber bipolar plate.

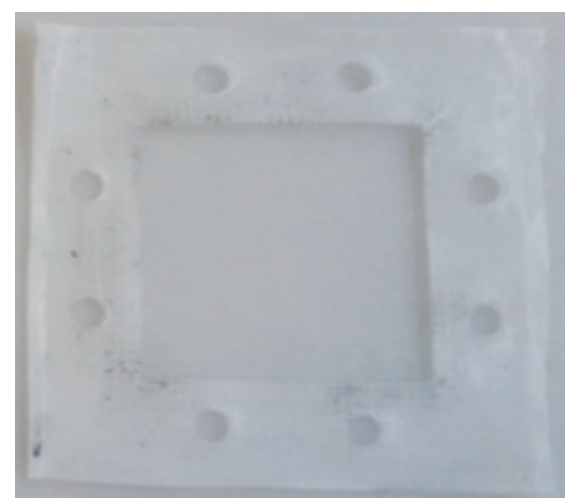

Fig. 6. (Color online) Teflon gasket.

\subsection{Bipolar plate}

Figure 5 shows a carbon fiber bipolar plate. The bipolar plate has a flow channel to guide hydrogen and oxygen and to conduct the current generated by the chemical reaction in the fuel cell. Traditionally, metal bipolar plates and graphite bipolar plates are used. Although a metal bipolar plate has excellent electrical conductivity, good ductility, and easy processing, it is prone to corrosion. That means that its resistance will increase over time. Graphite bipolar plates have good electrical conductivity and are not easily corroded, but their mechanical strength is poor and they are brittle, which causes difficulties in processing. The carbon fiber bipolar plate produced in this research has the advantages of high mechanical strength, electrical conductivity, corrosion resistance, and light weight.

\subsection{Gasket}

The gasket material is made of Teflon, which is resistant to acid and alkali, and is an electrical insulator. The gasket separates the anode from the cathode to avoid gas mixing. To avoid gas leakage, the gasket must be slightly larger than the bipolar plate. The central opening matches the MEA reaction area. Figure 6 shows the Teflon gasket. 


\subsection{MEA}

The MEA has a catalyst-coated membrane (CCM) in the middle and a gas diffusion layer in both directions. The Pt content of the CCM cathode is $0.4 \mathrm{mg} / \mathrm{cm}^{2}$ and that of the anode is $0.2 \mathrm{mg} / \mathrm{cm}^{2}$. The gas diffusion layer must have high conductivity, corrosion resistance, pressure resistance, gas permeability, and hydrophobicity. The hydrogen diffuses from the flow channel on the bipolar plate to the gas diffusion layer and reacts with the catalyst on the proton exchange membrane to produce hydrogen protons. The hydrogen protons react with the oxygen at the cathode end to become water as they pass through the CCM. Figure 7 shows the MEA.

\subsection{End plate}

A copper end plate was used for testing, as shown in Fig. 8. It has channels for gas inflow and outflow to introduce hydrogen or oxygen. The unreacted hydrogen or oxygen and the water produced by the reaction flow out of the end plate.

\section{Experimental Process}

There are five steps in this experiment: carbon fiber prepreg production, heat press forming, $\mathrm{CNC}$ processing, performance testing, and soaking in the phenolic resin and carbonization. The experimental process is shown in Fig. 9.

\subsection{Carbon fiber prepreg production}

Firstly, the carbon fiber cloth is cut to an appropriate size. The weights of the carbon fiber cloth, resin, and carbon powder are measured. The scale of the resin is $40 \%$ of the prepreg, and the scale of the carbon powder is $8 \%$ of the prepreg. The resin is mixed with carbon powder with an appropriate amount of methanol added. A blender is used to stir the mixture for $30 \mathrm{~min}$. The carbon fiber cloth is then coated with this mixture. The coated fiber cloth is allowed to dry until the methanol volatilizes. The carbon fiber prepreg is shown in Fig. 10.

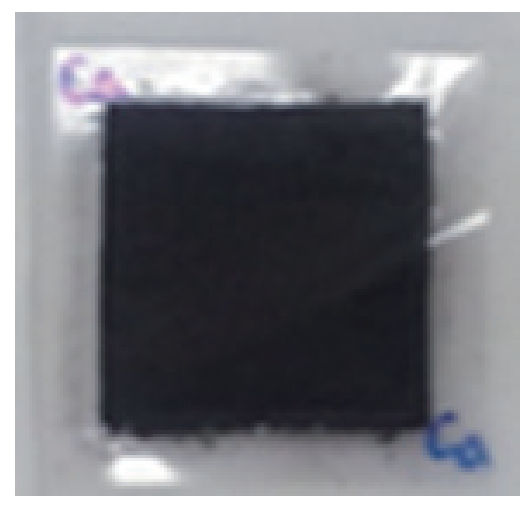

Fig. 7. (Color online) MEA.

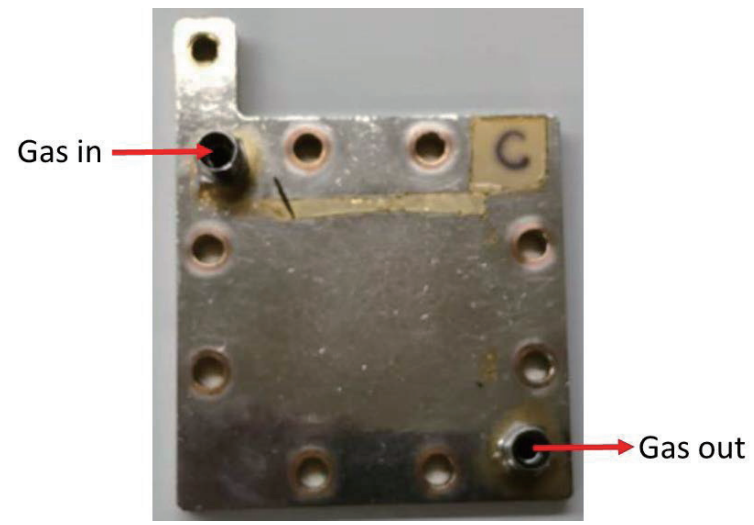

Fig. 8. (Color online) Copper end plate. 


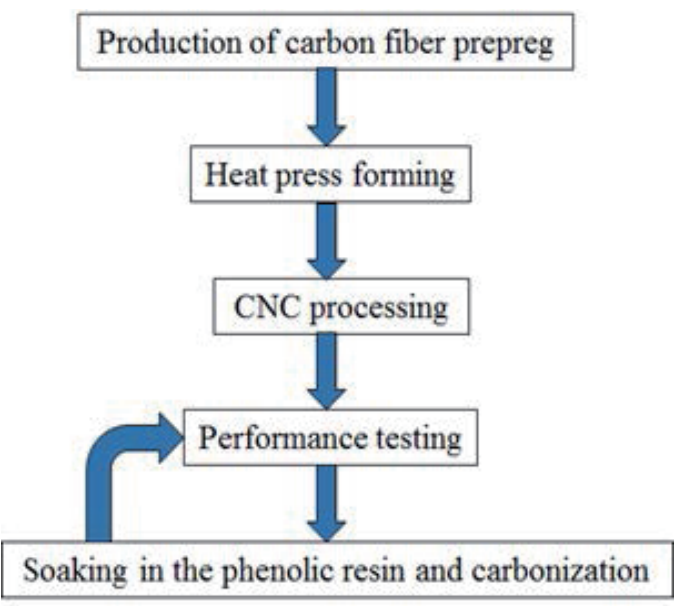

Fig. 9. (Color online) Carbon fiber bipolar plate construction process.

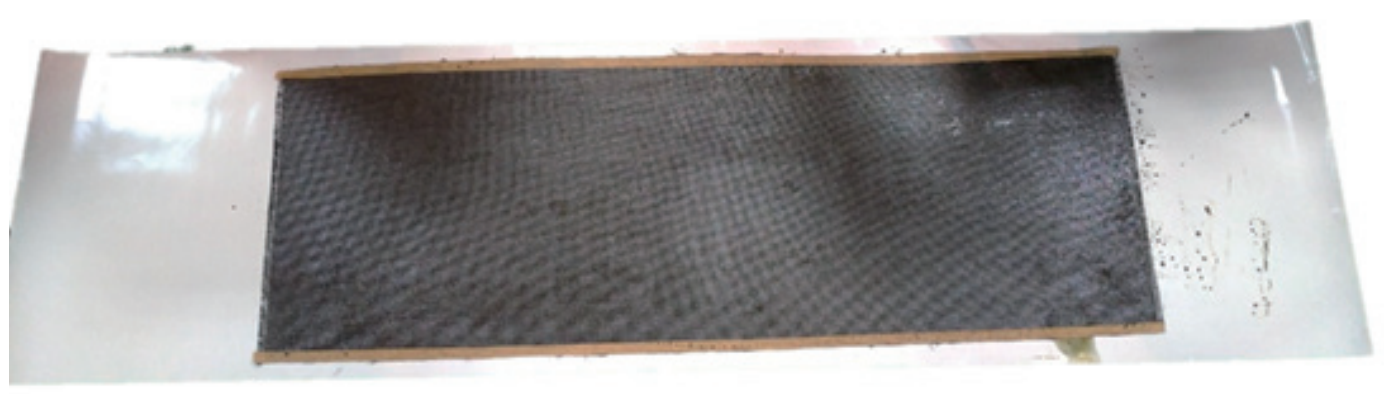

Fig. 10. (Color online) Carbon fiber prepreg.

\subsection{Heat press forming}

The prepreg cloth is cut into $30 \times 30 \mathrm{~cm}^{2}$ pieces, which are stacked layer by layer. A roller is used to squeeze out the bubbles between the fibers. The fiber pieces are then placed in a film tool on a heat press machine. Figure 11 shows the machine settings: the temperature is $150{ }^{\circ} \mathrm{C}$, the pressure is $150 \mathrm{~kg} / \mathrm{cm}^{2}$, and the processing time is $30 \mathrm{~min}$. After heat pressing, the carbon fiberboard is allowed to cool to room temperature.

\subsection{CNC processing}

The size and shape of the bipolar plates are drawn in AutoCAD and then imported into the engraving software to set the processing path and tools. After the setup is completed, a CNC engraving machine is used to carve the carbon fiber composite plate into the bipolar plate shape. Figure 12 shows that the $\mathrm{CNC}$ machine carves the carbon fiber composite plate. 

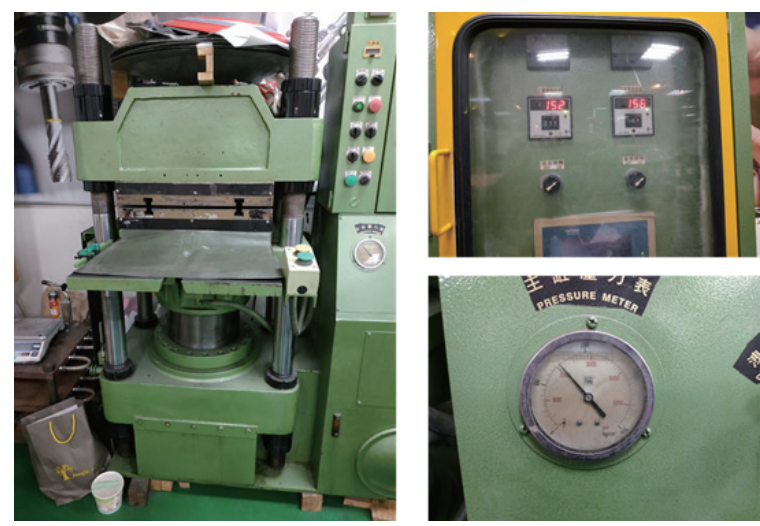

Fig. 11. (Color online) Heat press machine.

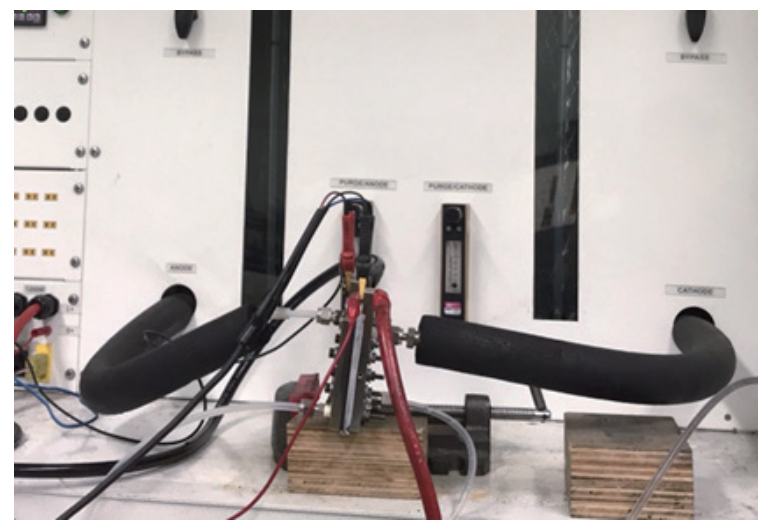

Fig. 13. (Color online) Setup for testing the fuel cell.

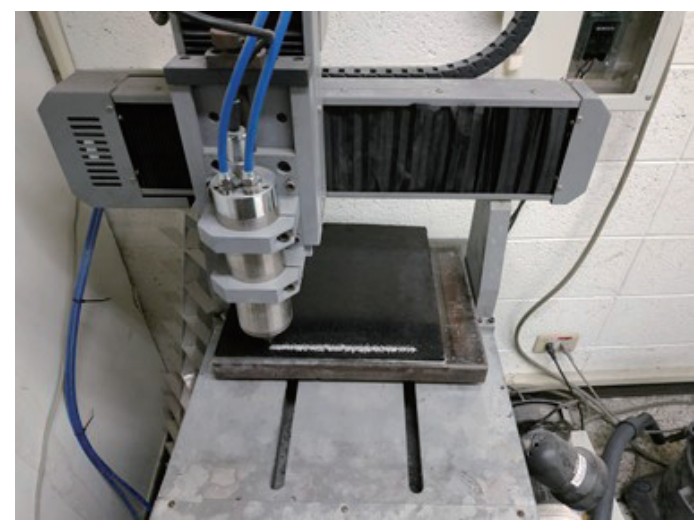

Fig. 12. (Color online) $\mathrm{CNC}$ machine.

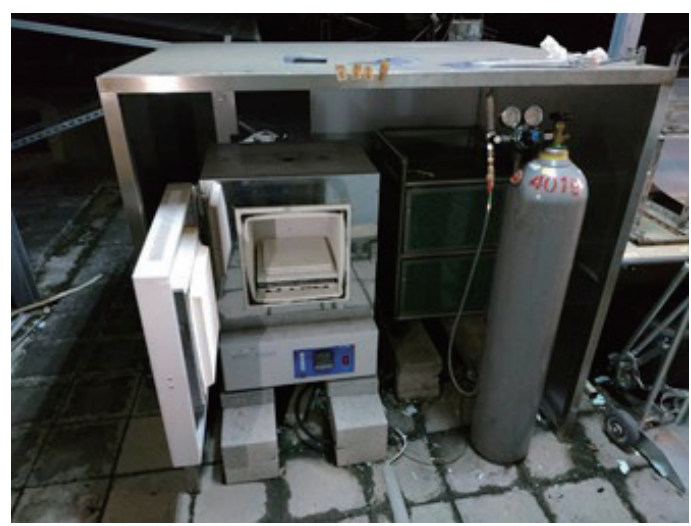

Fig. 14. (Color online) High-temperature furnace.

\subsection{Performance testing}

The carbon fiber bipolar plates are placed in the fuel cell to test their performance. In this experiment, the hydrogen flow rate at the anode is $300 \mathrm{sccm}$ and the oxygen flow rate at the cathode is $600 \mathrm{sccm}$. The gas is humidified and heated to $50{ }^{\circ} \mathrm{C}$. The setup used in the testing is shown in Fig. 13. If the bipolar plate performance is poor, the bipolar plate will be soaked in the phenolic resin and carbonized repeatedly. Finally, the bipolar plates with the best performance are stacked in the fuel cell and the performance of the fuel cell is tested.

\subsection{Soaking in the phenolic resin and carbonization}

The carbon fiber bipolar plate is soaked in resin for three days and then placed in air to dry, which is followed by heat pressing. The heat pressing temperature, pressure, and time are the same as those in the previous heat pressing procedure. After heat pressing is completed, the bipolar plate is placed inside a high-temperature furnace for carbonization, as shown in Fig. 14. The furnace is filled with nitrogen to prevent the oxidation of the bipolar plate, the 
carbonization temperature is set at $600{ }^{\circ} \mathrm{C}$, and the carbonization time is set to $30 \mathrm{~min}$. After the carbonization, the bipolar plate is allowed to cool to room temperature.

\section{Results and Discussion}

The weight of the carbon fiber bipolar plate is about half that of a graphite bipolar plate. The flexural strength of the uncarbonized bipolar plate is highest. Although the flexural strength of the bipolar plate carbonized twice is very low compared with that of the uncarbonized bipolar plate, it meets the DOE standard. ${ }^{(20)}$ The results of flexural strength tests are shown in Table 1. Figure 15 shows that the uncarbonized bipolar plate has the lowest performance The current density of the bipolar plate carbonized twice is higher than that of the graphite bipolar plate at the setting voltage of $0.5 \mathrm{~V}$. This means that the performance of the bipolar plate carbonized twice is better than that of the graphite bipolar plate. Figure 16 shows a schematic diagram of a stack of two fuel cells that use twice-carbonized bipolar plates. The performance of the fuel cell stack is shown in Fig. 17. The fuel cells in the stack are connected in series to increase the working voltage and fuel cell power. In the future, this design will be able to produce a fuel cell stack that can be used as a power generation device with high chemical stability, good conductivity, and light weight.

Table 1

Maximum flexural strength of bipolar plates.

\begin{tabular}{lcccc}
\hline Test No. & Uncarbonized & One carbonization process & Two carbonization processes & DOE 2020 target \\
\hline 1 & $467.5 \mathrm{MPa}$ & $73.5 \mathrm{MPa}$ & $34.2 \mathrm{MPa}$ & $>25 \mathrm{MPa}$ \\
2 & $448.2 \mathrm{MPa}$ & $68.7 \mathrm{MPa}$ & $47.5 \mathrm{MPa}$ & \\
3 & $497.2 \mathrm{MPa}$ & $63.5 \mathrm{MPa}$ & $40.6 \mathrm{MPa}$ & \\
4 & $452.9 \mathrm{MPa}$ & $62.4 \mathrm{MPa}$ & $33.0 \mathrm{MPa}$ & \\
5 & $482.8 \mathrm{MPa}$ & $69.3 \mathrm{MPa}$ & $38.3 \mathrm{MPa}$ & \\
\hline Average & $469.7 \mathrm{MPa}$ & $67.5 \mathrm{MPa}$ & $38.7 \mathrm{MPa}$ & \\
\hline
\end{tabular}

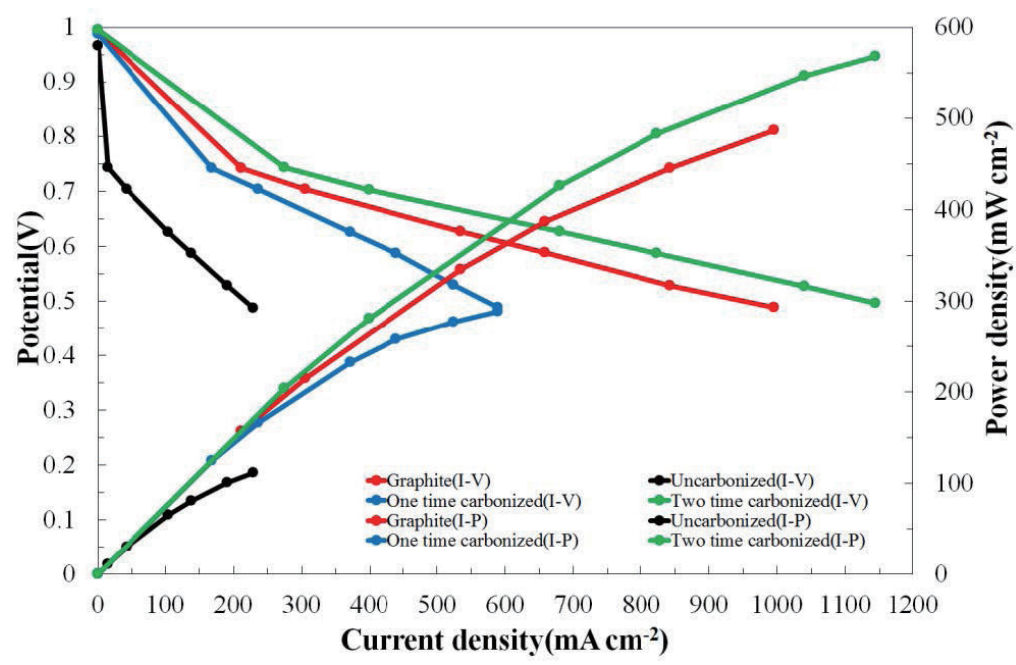

Fig. 15. (Color online) Performance of graphite and other bipolar plates. 


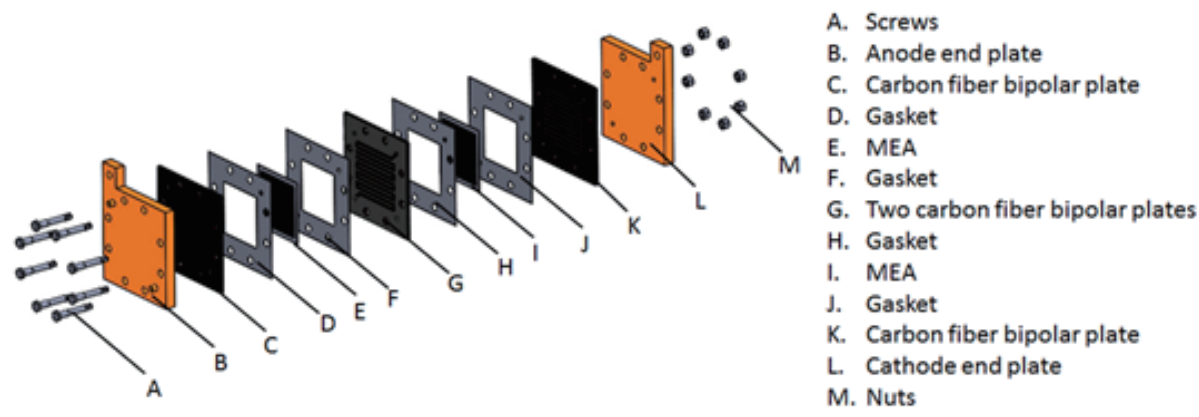

Fig. 16. (Color online) Schematic of stack of two fuel cells.

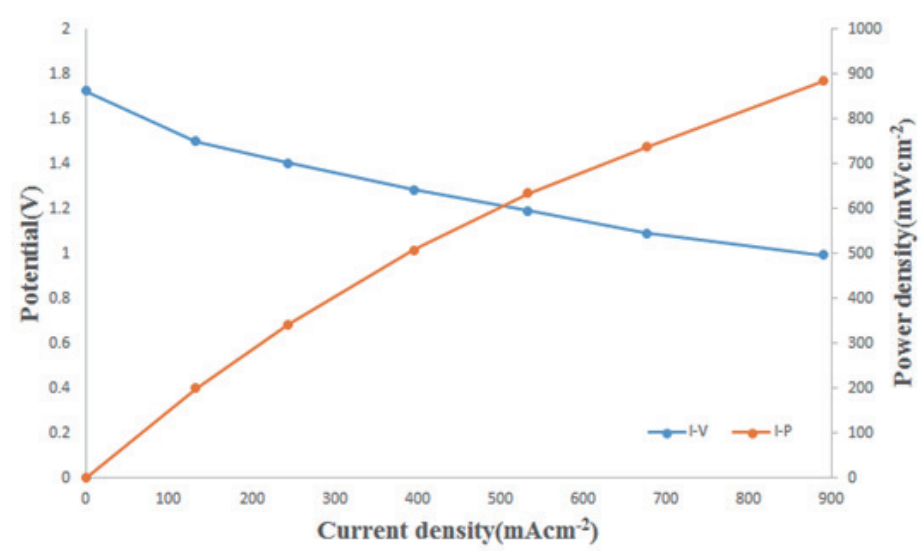

Fig. 17. (Color online) Performance of fuel cell stack.

\section{Conclusions}

In this research, carbon fiber composite bipolar plates were developed to replace the graphite bipolar plates in fuel cell stacks. We used a plain-weave graphite fiber composite bipolar plate fabricated using phenolic resin mixed with carbon nanotube powder. The low conductivity of the resin resulted in the low performance of the composite bipolar plate. To eliminate some of the resin, the carbonization process was applied. After carbonization, the conductivity of the composite bipolar plate increased. The maximum flexural strengths of the uncarbonized bipolar plate and the bipolar plates carbonized once and twice passed the DOE 2020 target. The fuel cell stack assembled with the bipolar plate carbonized twice could work with high performance. This also shows the feasibility and potential of the carbon fiber composite fuel cell stacks for future applications.

\section{Acknowledgments}

The experimental activities in this study were supported by the Air Conditioning and Energy Department of National Chin-Yi University of Technology (NCUT), Taiwan, and the Ministry of Science and Technology of Taiwan (MOST 108-2221-E-167-014 and MOST 109-2221-E-167006). 


\section{References}

1 M. W. Ellis, M. R. Von Spakovsky, and D. J. Nelson: Proc. 2001 IEEE Fuel Cell Systems: Efficient, Flexible Energy Conversion for the 21st Century (IEEE, 2001) 1808.

2 T. Wilberforce, Z. E. Hassan, E. Ogungbemi, O. Ijaodola, F. N. Khatib, A. Durrant, J. Thompson, and A. B. A. G. Olabi: Renewable Sustainable Energy Rev. 111 (2019) 236. https://doi.org/10.1016/j.rser.2019.04.081

3 M. Kim, J. Choe, J. W. Lim, and D. G. Le: Compos. Struct. 132 (2015) 1122. https://doi.org/10.1016/ j.compstruct.2015.07.038

4 J. W. Lim, M. Kim, and D. G. Lee: Compos. Struct. 108 (2014) 757. https://doi.org/10.1016/ j.compstruct.2013.10.021

5 M. Kim, J. W. Lim, and D. G. Lee: Compos. Struct. 96 (2013) 569. 10.1016/j.compstruct.2012.09.017

6 B. G. Kim, J. W. Lim, and D. G. Lee: Int. J. Hydrogen Energy. 36 (2011) 3087. https://doi.org/10.1016/ j.ijhydene.2010.11.102

7 E. A. Cho, U. S. Jeon, H. Y. Ha, S. A. Hong, and I. Hoh: J. Power Sources 125 (2004) 178. https://doi. org/10.1016/j.jpowsour.2003.08.039

8 D. Lee, J. Choe, S. Nam, J. W. Lim, I. Choi, and D. G. Lee: Compos. Struct. 160 (2017) 976. https://doi. org/10.1016/j.compstruct.2016.10.107

9 M. Kim, J. Choe, J. W. Lim, and D. G. Lee: Compos. Struct. 132 (2015) 1122. https://doi.org/10.1016/ j.compstruct.2015.07.038

10 S. H. Liao, C. H. Hung, C. C. M. Ma, C. Y. Yen, Y. F. Lin, and C. C. Weng: J. Power Sources 176 (2008) 175. https://doi.org/10.1016/j.jpowsour.2007.10.064

11 B. K. Kakati, D.Sathiyamoorthy, and A.Verma: Int. J. Hydrogen Energy 35 (2010) 4185. https://doi.org/10.1016/ j.ijhydene.2010.02.033

12 H. E. Lee, S. H. Han, S. A. Song, and S. S. Kim: Compos. Struct. 134 (2015) 44. https://doi.org/10.1016/ j.compstruct.2015.08.037

13 Y. Qin, G. Liua, Y. Chang, and Q. Du: Appl. Therm. Eng. 144 (2018) 411.

14 A. A. Abdel-Rehim: Energy Convers. Manage. 198 (2019) 111906. https://doi.org/10.1016/ j.enconman.2019.111906

15 A. Polak, G. Greczka, and T. Pilat: J. Marine Eng. Technol. 16 (2017) 283. https://doi.org/10.1080/20464177.20 17.1381061

16 J. T. Pukrushpan, A. G. Stefanopoulou, and H. Peng: Proc. 2002 American Control Conf. (2002). https://doi. org/10.1109/ACC.2002.1025268

17 T. Wilberforce, Z. El-Hassan, F. N. Khatib, A. A. Makky, A. Baroutaji, J. G. Carton, J. Thompson, and A. G. Olabi: Int. J. Hydrogen Energy 42 (2017) 25639. https://doi.org/10.1016/j.ijhydene.2017.06.091

18 N. Rajalakshmi and M. R. K. S. Dhathathreyan: J. Power Sources 112 (2002) 331. https://doi.org/10.1016/ S0378-7753(02)00352-X

19 G. Giacoppo, S. Hovland, and O. Barbera: Appl. Energy 242 (2019) 1683. https://doi.org/10.1016/ j.apenergy.2019.03.188

20 U.S. Department of Energy: DOE Technical Targets for Polymer Electrolyte Membrane Fuel Cell Components (2016).

\section{About the Authors}

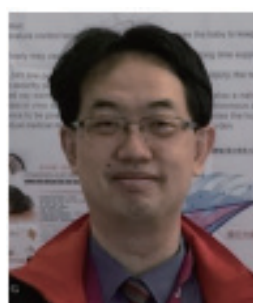

Yean-Der Kuan is a distinguished professor and a former chairperson (2013/02-2019/01) of the Department of Refrigeration, Air-Conditioning and Energy Engineering at National Chin-Yi University of Technology, Taichung, Taiwan. He received his Ph.D. degree from the Department of Mechanical and Aerospace Engineering at the University of Missouri, USA, in 2000. Currently, Prof. Kuan is also the director of the Taiwan Society of Heating, Refrigeration and Air Conditioning, the director of the Taiwan Energy Association, the director of the Taiwan Association for Hydrogen Energy and Fuel Cells, and a member of the American Society of Heating, Refrigerating, and Air-Conditioning. His research interests include the fields of energy saving and renewable energies, and air-conditioning components and systems. 
Chong-Kai Wang received his diploma from the Department of Refrigeration, Air-Conditioning and Energy Engineering, National Chin-Yi University of Technology (NCUT), Taiwan in 2019. Since 2019, he has been studying toward his master's degree at NCUT. His study focuses on fuel cells and the procedure of making carbon fiber composite boards.

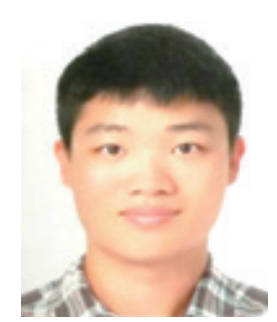

Cheng Yang is an undergraduate student in the Department of Refrigeration \& Air Conditioning and Energy Engineering, National Chin-Yi University of Technology, Taiwan.

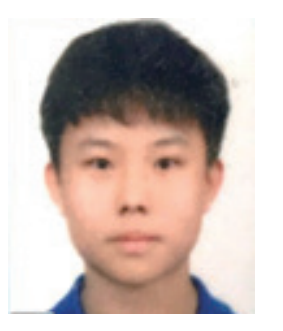

Po-Cheng Lee is an undergraduate student in the Department of Refrigeration \& Air Conditioning and Energy Engineering, National Chin-Yi University of Technology, Taiwan.

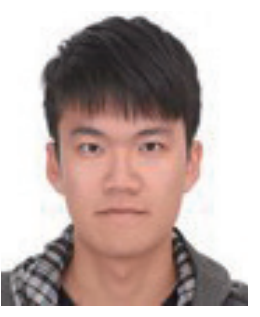

Yu-Sheng Siao is an undergraduate student in the Department of Refrigeration \& Air Conditioning and Energy Engineering, National Chin-Yi University of Technology, Taiwan.

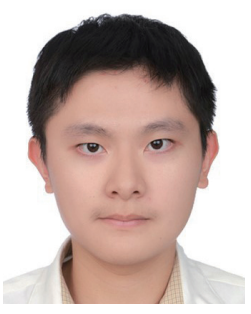

Cheng-Yi Lee is an undergraduate student in the Department of Refrigeration \& Air Conditioning and Energy Engineering, National Chin-Yi University of Technology, Taiwan. 